\title{
Long Run Relationship between Capital Market and Banking Sector-A Cointegration on Federal Bank
}

\author{
A. Anjali and K.T. Thomachan
}

\begin{abstract}
This paper examines the long run relationship between the capital market and banking sector. India has a large investment contribution in capital market. It is vital to the functioning of an economy. The object of the study is to analyze the long run relationship between the stock price of federal bank and composite price of capital market represented by NIFTY. The data used for the purpose is secondary source. An empirical investigation is carried out using daily data of ten years ranging from $1^{\text {st }}$ January 2005 to $31^{\text {th }}$ December 2014. The data used in the present study have been taken from the official website of National Stock Exchange. The major statistical tools used in the study are Unit Root Test, Granger Causality /Block Exogenity Test, Cointegration analysis, Impulse Response function and Error Variance decomposition using the software E-views. Applying the Dickey Fuller Tests to determine the stationality it has been found that both time series are non stationary. Johnsen Cointegration analysis shows that there is unidirectional movement between NIFTY and Federal Bank index. To further investigate the lead lag relationship between the two by Granger Causality/Block Exogenaty test and to identify the short run relationship impulse response function and variance decomposition is conducted. From the study it is conclude that the effect in the banking sector leads to the movement of banking sector but no vice versa.
\end{abstract}

Keywords--- Federal Bank Price, NIFTY Price, Unit Root, Granger Causality, Cointegration, Impulse Response, Variance Decomposition

\section{INTRODUCTION}

$\mathrm{T}$ HE capital market is one of the important segment in promoting and sustaining economic growth through the mobilization of long term saving in the Indian financial system. The financial system is an effective exchange of goods and service, allocation of resources and monitoring of corporate management through capital market. During the last 20 years the capital market in India has witnessed growth in volume of funds raised as well as on transaction. Throughout the Indian history capital market played a crucial role in the

A. Anjali, Assistant Professor, Department of Business Management, St Joseph's College, Devagiri. E-mail:anjalianjitha@gmail.com

K.T. Thomachan, Associate Professor, Department of Economics, St Joseph's College, Devagiri. E-mail:thomachandevagiri@gmail.com

DOI: 10.9756/BIJIEMS.8020 periods of technological progress and economic development. The introduction of liberalization, privatization, and globalization policy has made tremendous change in the global and Indian financial market. India remains a promising country for the investors since foreign investment is permitted in Indian capital market and this growth leads to the economic development. The government of India and SEBI has taken a number of measures to improve the working of the Indian stock exchange and to make it more progressive and vibrant.

Capital market plays a pivotal role in the growth of economy and meeting country's socio economic goals. Capital market is a financial market for the buying and selling of the long term debt or equity backed securities. It has two independent segments the primary market and secondary market. Primary market is set up to helps the industry to raise funds by issuing different types of security and the Secondary market is to the subsequent sale and purchase of securities. The leading stock exchanges in India are Bombay stock exchange and national stock exchange. In this Bombay stock exchange is the oldest and largest stock exchange. The advent of technology to the markets has been largely attributed to the national stock exchange and it introduced the screen based trading and settlement system, supported by the state of the art technology platform.

The banking sector in India is originated in the $18^{\text {th }}$ century. The rapid growth in the economy of India revitalized the banking sector in India, which has a strong contribution from all the three sectors of banks, namely government banks private banks and foreign banks. Bank nifty represent 12 most liquid and large capitalized stock from the banking sector which trade on the national stock exchange. It provides investor and market intermediaries a bench mark that capture the capital market performance in Indian banking sector.

The federal bank limited is a major Indian commercial bank in private sector. It is the fourth largest bank in India in terms of capital base. The banking sector has a great role in the capital market. The result of the study facilitate in identifying whether the movement of banking sector is the result of NSE nifty or wise verse.

The object of the study is to analyze the long run relationship between the stock price of federal bank and composite price of capital market represented by NIFTY.

The paper is structured as follows: In section 2 reviews of literature on relating with the study and methodology. In section 3, the data and methodology used for the study is stated. In the section 4, the empirical analysis and result of the 
data for the study is included. In the final section, the conclusion of the study is presented.

\section{LITERATURE REVIEW}

Ciner (2001) In their study examines the long-term linkages between the prices of the gold and silver futures contracts traded on the TOCOM. Statistical findings indicate that the frequently cited long-term stable relationship between the prices of gold and silver has disappeared. This finding should be of relevance to participants in gold and silver markets. It is indicated that these two markets should be approached as separate markets and changes in the gold to silver ratio should not be used to predict prices in the future.

Kutsuna et al (2007) the study is conducted on the role of banking relationship access to equity capital markets evidence from Japan's main bank system. The main objective is bank relationship can be an efficient way for the investment bank to acquire information generated by main bank but may give rise to conflict of interest from the study come to the conclusion that no evidence of interest or self dealing for either the main bank or the investment bank.

Majali and assaf (2014) this study is conducted with an aim to investigate whether the Amman stock exchange (ASE)performance as measured by the stock price index, is effected by a set of macroeconomic variables. The data used are quarterly data from 1992-2014. The affect exist or not is tested by Johansen co-integration test and vector error correction model (VECM), Impulse response function (IRF) and variance decomposition (VD) are employed. The evidence implies that an increase in the weighted average interest rate on time deposit in the banking system has a greater effect on the stock price index than other macro economic and financial variables.

Zhunge (2010) there study investigate economic linkage between the China and Africa. For the study the data are used 1985-2009 GDP rate. In their study they use Cointegration, VEC model, Granger Causality list, generalized impulse response function and variance decomposition. They conclude their study that their relationship between the two countries is insignificant.

\section{METHODOLOGY AND DATA}

The empirical investigation is carried out using daily data for the period of 10 years ranging from $1^{\text {st }}$ January 2005 and $31^{\text {st }}$ December 2014. The data for the study has been taken from the official website of National Stock Exchange.

The major statistical tools used in the study are unit root test, Granger causality/Block Exogeneity test, Cointegration analysis, Impulse response function and Error Variance decomposition.

\section{Testing for Unit Roots}

A number of issues should be addressed when using time series data for regression analysis. One important issue discussed in the recent time series literature is the phenomenon of nonstationarity. If the time series variables used in the regression analysis are nonstationary, regressing one time series on another using ordinary least squares will give rise to the problem of spurious regression; that is, absence of any meaningful relation between variables. Therefore, it is necessary to examine stationarity of the time series variables before using them in regression analysis. A number of testing procedures known as unit root tests are available in the literature to determine stationarity of time series variables. The present study utilizes the most popular test for unit roots known as Dickey Fuller tests. The test is available in different forms depending on whether the variable under consideration has no intercept, intercept and intercept and trend. We use the most general form of the test namely Augmented Dickey Fuller test. The form of the test is given as

$$
\Delta y_{t}=\beta_{1}+\beta_{2} t+\gamma y_{t-1}+\sum_{i=1}^{n} \alpha_{i} \Delta y_{t-i}+\varepsilon_{t}
$$

Where the test statistic is known as the $\hat{\tau}$ statistic based on $\gamma$ from equation (1)

\section{Johansen Cointegration Test}

Given a group of nonstationary time series, our interest is to determine whether the series are cointegrated, and if they are, in identifying the cointegrating (long run equilibrium) relationships. In other words, cointegration analysis is used to assess whether there exists a long run or equilibrium relationship between nonstationary time series variables. The widely used procedure for determining the existence of cointegration among a set of nonstationary I (1) variables is the Johansen procedure. In the Johansen framework the first step is the estimation of a $\mathrm{p}^{\text {th }}$ order VAR in $\mathrm{k}$ variables.

$$
\mathrm{Y}_{\mathrm{t}}=\pi_{1} \mathrm{Y}_{\mathrm{t}-1}+\pi_{2} \mathrm{Y}_{\mathrm{t}-2}+\ldots \ldots \ldots \ldots \pi_{\mathrm{p}} \mathrm{Y}_{\mathrm{t}-\mathrm{p}}+\varepsilon_{\mathrm{t}}
$$

where $Y_{t}$ is a $(k x 1)$ vector of nonstationary $I$ (1) variables, $\pi_{\mathrm{i}}$ is an (nxn) matrix of parameters and $\varepsilon_{\mathrm{t}}$ is an (nx1) vector of innovations.

Equation (2) can be reparameterized in to a VECM form as

$$
\Delta \mathrm{Y}_{\mathrm{t}}=\pi \mathrm{Y}_{\mathrm{t}-1}+\Gamma_{1} \Delta \mathrm{Y}_{\mathrm{t}-1}+\Gamma_{2} \Delta \mathrm{Y}_{\mathrm{t}-2}+\ldots \ldots \ldots+\Gamma_{\mathrm{p}-1} \Delta \mathrm{Yt}_{-(\mathrm{p}-1)}+\varepsilon_{\mathrm{t}}(3)
$$

where $\pi=\pi_{1}+\pi_{2}+\ldots \ldots \ldots \ldots \pi_{\mathrm{p}-1}$, and $\Gamma_{\mathrm{i}}=-\left(\pi_{\mathrm{i}+1}+\pi_{\mathrm{i}+2}\right.$ $\left.+\ldots \ldots \ldots \ldots \ldots \pi_{\mathrm{p}}\right)$

Johansen suggests two test statistics namely $\lambda_{\max }$ statistics and $\lambda_{\text {trace }}$ statistics to determine the cointegrating rank (number of cointegrating relationships). Both test statistcs establishes the rank of the $\pi$ matrix based on its Eigen values (and hence the number of cointegrating relationships)

$$
\begin{aligned}
& \lambda_{\text {trace }(r)}=-T \sum_{i=r+1}^{k} l_{n}\left(1-\hat{\lambda}_{i}\right) \\
& \lambda_{\max (r, r+1)}=-T l_{n}\left(1-\hat{\lambda}_{r+1}\right)
\end{aligned}
$$

A decision regarding the existence of a long run relationship is based on the value of the test statistic obtained from sample. 


\section{Granger Causality Test}

Granger causality test seeks to determine whether past values of a variable helps to predict changes in another variable. To implement Granger Casualty test consider a bivariate VAR model in $\mathrm{X}_{\mathrm{t}}$ and $\mathrm{Y}_{\mathrm{t}}$ with $\mathrm{p}$ lags in both variables:

$$
\begin{aligned}
& Y_{t}=\sum_{i=1}^{p} \alpha_{i} Y_{t-i}+\sum_{i=1}^{p} \beta_{i} X_{t-i}+\varepsilon_{1 t} \\
& X_{t}=\sum_{i=1}^{p} \lambda_{i} X_{t-i}+\sum_{i=1}^{p} \delta_{i} Y_{t-i}+\varepsilon_{2 t}
\end{aligned}
$$

There are four possibilities in the system of equations (6) and (7) given above. Unidirectional causality from $Y_{t}$ to $X_{t}$ if the estimated $\delta \mathrm{i}$ in equation (7) are statistically different from zero as a group and the set of estimated $\beta$ i coefficients in (6) is not different from zero. Unidirectional causality from $\mathrm{X}_{\mathrm{t}}$ to $\mathrm{Y}_{\mathrm{t}}$ if the set of $\beta$ i coefficients in (6) is statistically different from zero and the set of $\delta i$ is not statistically different from zero. Bidirectional causality is indicated when the sets of $\mathrm{X}_{\mathrm{t}-\mathrm{i}}$ and $\mathrm{Y}_{\mathrm{t}}$ $i$ coefficients are statistically different from zero in both equations. There is no causality when $\mathrm{X}_{\mathrm{t}-\mathrm{i}}$ and $\mathrm{Y}_{\mathrm{t}-\mathrm{i}}$ coefficients are not statistically different from zero. If all the variables in the VAR are stationary a direct way to test Granger Causality is to use a standard $\mathrm{F}$ test given as:

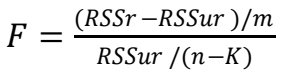

It is straight forward to generalize this notion to $\mathrm{k}$ variable case described earlier (equation 2)

The VAR model is used to implement Granger Causality test provided that the variables are stationary. If the variables are nonstationary, but not cointegrated, the entire model is reformulated in first differences. However, if the variables are nonstationary but cointegrated, there must be a short run and long run causality which cannot be captured by the standard first difference VAR model. In this case, one can implement the Granger causality test in the VECM framework by reparameterizing the VAR model as VECM.

When more than two variables are involved, Granger causality/ Block Exogeneity Wald test is useful for detecting whether to incorporate additional variables in to the VAR/VECM. In this case the test statistics is given as:

$$
\text { (T -3P-1) }(\log / \text { sre/-log/ } \mathrm{un} /) \sim \chi^{2}(2 \mathrm{P})
$$

Where $\mathrm{T}$ is the number of observations; $\Sigma$ un is variance/covariance matrices of the unrestricted VAR system; $\Sigma \mathrm{re}$ is variance/covariance matrices of the restricted system where the lag of a variable is excluded from the VAR system; and $\mathrm{P}$ is the number of lags of the variable that is excluded from the VAR system.

\section{Impulse Response Function and Error Variance Decomposition}

Granger Causality test, though establishes the causality between variables, is not sufficient to establish the nature and strength of relationship between variables. To infer more about these issues, we analyze the impulse response function and error variance decomposition. Shin and Pesaran defines the impulse response function as, "An impulse response function measures the time profile of the effects of shocks at a given point in time on the (expected) future values of variables in a dynamic system".

The impulse response function is defined as:

$$
\operatorname{IR}\left(\mathrm{m}, \mathrm{h}, \mathrm{Z}_{\mathrm{t}-1}\right)=\mathrm{E}\left(\mathrm{Y}_{\mathrm{t}+\mathrm{m}} / \mathrm{e}_{\mathrm{t}}=\mathrm{h}, \mathrm{Z}_{\mathrm{t}-1}\right)-\mathrm{E}\left(\mathrm{Y}_{\mathrm{t}+\mathrm{m}} /=\mathrm{Z}_{\mathrm{t}-1}\right)(10)
$$

Where $\mathrm{m}$ denotes the time, $\mathrm{h}=(\mathrm{h} 1 \ldots . . \mathrm{hm})$ is $\mathrm{nx} 1$ vector denotes the size of shock, $\mathrm{Z}_{\mathrm{t}-1}$ denotes accumulative information about the economy from the past to time $t-1$.

A major problem with the IRF is identification of impulse responses. Thus econometricians impose additional restrictions on the VAR system for identification. One possible identification restriction is to use the Choleski decomposition that a series has no contemporaneous effect on other series. When this assumption is not satisfied, IRF will change with ordering of endogenous variables. There are two approaches to deal with this problem. One is to use the generalized impulse response function. The second is to use the ordering of the variables according to a set of rules suggested by Enders.

According to Enders (2010) the forecast error variance decomposition tells us the proportion of the movement ina sequence due to its "own" shocks versus shocks to the other variables. Therefore variance decomposition defines the relative importance of each random innovation in affecting the variables in the VAR.

\section{EMPIRICAL ANALYSIS AND RESULTS}

The stock price of Nifty and Federal bank for the $1^{\text {st }}$ January 2005 to $31^{\text {st }}$ December 2014 have been subjected to a logarithmic transformation and the series obtained are designated as Log Nifty and Log Fed respectively.

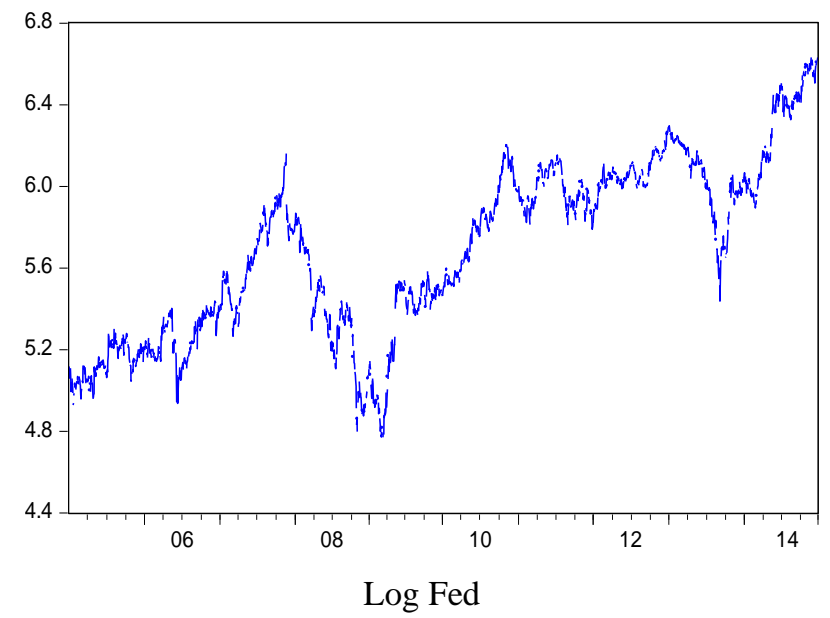




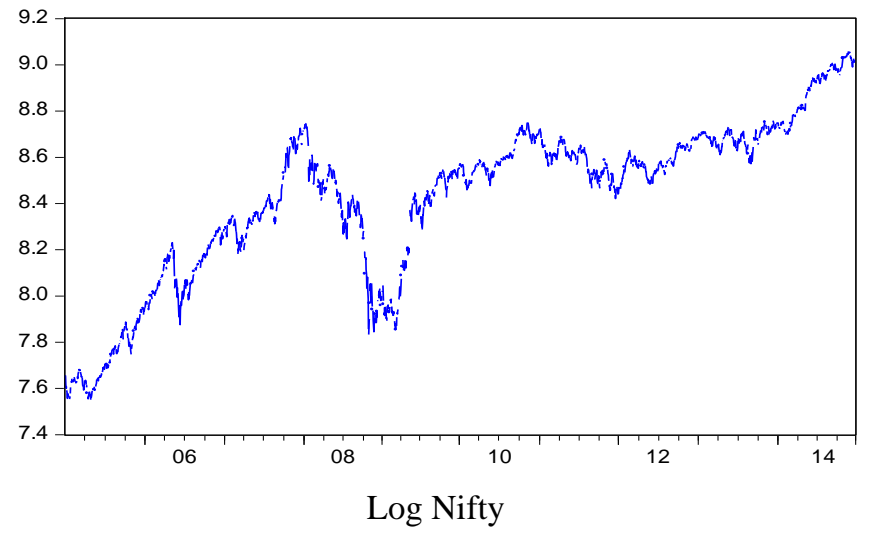

Unit Root Test

When time series variables are used in econometric analysis it is necessary to ensure that the variables are stationary to guard against spurious regression. If the variables are nonstationary, they should be made stationary by differencing before using them in the regression analysis. One exception to this is the case of cointegrated variables. If the variables are cointegrated then they could be directly used in the regression analysis without any spurious regression problem. Unit root tests are the most popular techniques used to detect nonstationarity. We use Augmented Dickey Fuller tests on log of both Nifty and Federal Bank stock indices in level and first differences to detect nonstationarity. The result clearly indicates that both series are nonstationary in level but stationary in first differences.

Table 1: Test Result of Unit Root Test

\begin{tabular}{|l|l|}
\hline Variable & Test statistic \\
\hline Log FEDERAL Price & $-2.725116(0.2263)$ \\
\hline$\Delta$ log FEDERAL Price & $-46.35146(0.0000)^{*}$ \\
\hline Log NSE NIFTY & $-2.527008(0.3149)$ \\
\hline$\Delta \log$ NSC NIFTY & $-46.68983(0.0000)^{*}$ \\
\hline
\end{tabular}

*indicate significance at $1 \%$ level

Figures in the bracket are $\mathrm{P}$ values

\section{Cointegration Analysis}

Cointegration analysis is used to identify long run relationship between variables. Johansen system cointegration analysis has been used in the present study to identify cointegration between Log Nifty and Log Fed stock indices. Both the $\lambda_{\max }$ and $\lambda_{\text {trace }}$ statistics accepts the null hypothesis of no cointegration between variables.

Table 2: Test result of Unrestricted Cointegration Rank Test (Trace)

\begin{tabular}{|l|l|l|l|}
\hline Hypothesis & Eigen Value & Trace Statistics & Max-Eigen value \\
\hline None & 0.003840 & $\begin{array}{l}11.01262 \\
(.2107)\end{array}$ & $9.499148(.2469)$ \\
\hline Atmost 1 & 0.000613 & $\begin{array}{l}1.513469 \\
(.2186)\end{array}$ & $\begin{array}{l}1.513469 \\
(0.2186)\end{array}$ \\
\hline
\end{tabular}

\section{Granger Causality Test}

Since no long run relationship exists between the variables, the series have been tested for short run relationship using Granger causality test. The test result rejects the null hypothesis that Log Nifty does not Granger causes Log Fed but accepts the null hypothesis that Log Fed does not Granger cause Log Nifty. Thus we conclude that Log Nifty granger causes Log Fed, that is, there is a unidirectional causality from Log Nifty to Log Fed.

Table 3: Test Result of Granger Causality Test

\begin{tabular}{|l|l|l|}
\hline Null Hypothesis & Observation & F-statistics \\
\hline $\begin{array}{l}\Delta \text { LOG FED does not } \\
\text { granger cause } \Delta \text { LOG }\end{array}$ & & 15.1737 \\
NIFTY & 2479 & $(0.0000)$ \\
\cline { 1 - 1 } $\begin{array}{l}\Delta \text { LOG NIFTY does } \\
\text { not granger cause } \Delta\end{array}$ & & 0.28615 \\
LOG FEDERAL & & $(0.7512)$ \\
\hline
\end{tabular}

Impulse Response and Error Variance Decomposition

Granger causality will not tell us the complete story about the interactions between the variables in a VAR system. To further explore the nature of interactions between variables we use two often used techniques in the context of VAR namely impulse response functions and error variance decomposition. We estimate these quantities from the VAR model in Log Nifty and Log Fed reformulated in first differences in the log of variables.

\section{Variance Decomposition}

Variance decomposition indicates how much of the predict error variance can be explained by exogenous shock of other variable. Result is shown for a 10 year period using Cholesky Decomposition. It is clear that Fed has little impact on Log Nifty whereas Log Nifty has considerable impact on Log Fed.

\section{Test Result of Error Variance Decomposition VAR}

\section{Variance Decomposition}

Percent DLOGFED variance due to DLOGFED

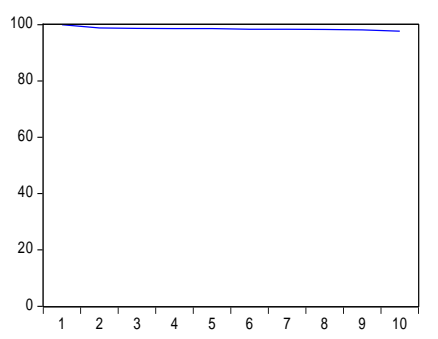

Percent DLOGNIFTY variance due to DLOGFED

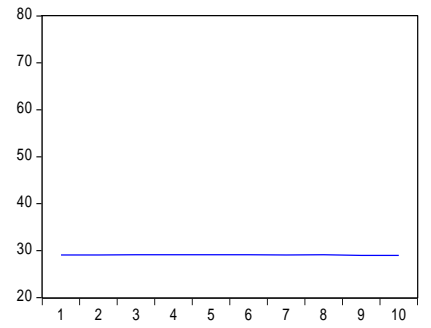

Percent DLOGFED variance due to DLOGNIFTY

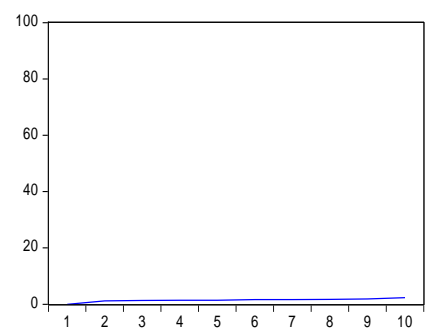

Percent DLOGNIFTY variance due to DLOGNIFTY

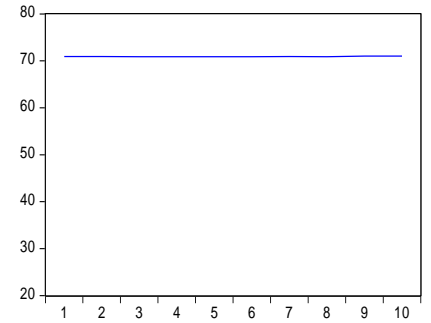




\section{Impulse Response Functions}

Variance decomposition explained the proportion of variance in one variable that is explained by the other variables, but the more specific effect is remained unknown. Impulse response function is thus employed to further analyze the effect. the impulse response function examine the dynamic behavior of one variable after exogenous change in one of the other variable. The results is shown is illustrated in the graph, in response to a positive standard deviation shock in itself. It is clear that the impact is minimal on both Log Nifty and Log Fed.

Test Result of Impulse Response of Log Fed and Log Nifty Response to Cholesky One S.D. Innovations \pm 2 S.E.
Response of DLOGFED to DLOGFED

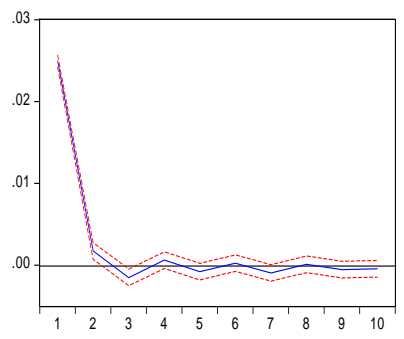

Response of DLOGNIFTY to DLOGFED

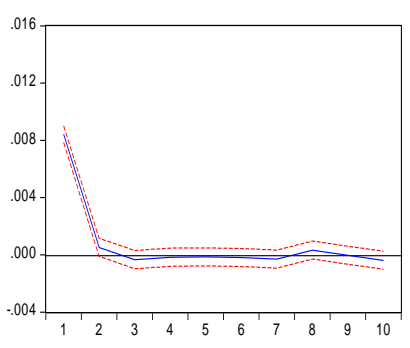

Response of DLOGFED to DLOGNIFTY

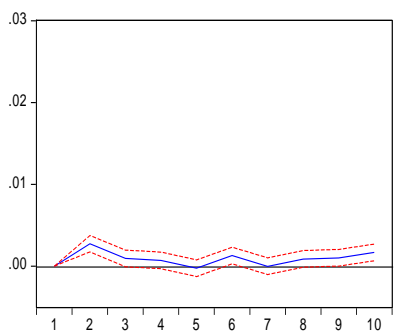

Response of DLOGNIFTY to DLOGNIFTY

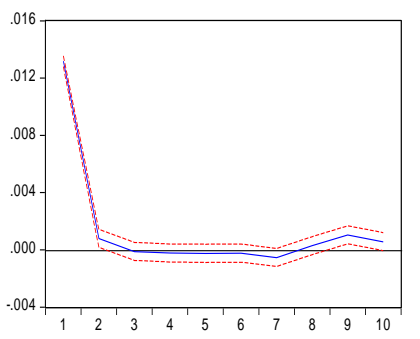

\section{CONCLUSION}

This paper investigated the long run relationship between stock price of Federal Bank and NSE Nifty for a period of ten years of daily data from $1^{\text {st }}$ January 2005 to $30^{\text {th }}$ December 2014. The Augmented dickey fuller unit root test concluded that stock price of Federal Bank and NSE Nifty are non stationary but stationary in first difference. The Johansen's cointegration Test is conducted to examine the long run relationship using trace and Max-Eigen value statics. Granger Causality Test concluded that there is unidirectional causality between them. From Variance decomposition the result states that $\log$ fed has little impact on Log nifty whereas it has considerable impact on Log fed and in case of impulse response both Log nifty and Log fed has only minimal impact. The result suggests that there is unidirectional effect on Log nifty and Log fed and also there is no long term relationship between these two variables.

\section{REFERENCE}

[1] Gujarati Damodar N. \& Sangeetha, "Basic Econometrics", Fourth Edition, McGraw Hill Pvt. Ltd., New Delhi, 2011.

[2] Walter Ender, Applied Econometric Time Series, $4^{\text {th }}$ edition, (2014).

[3] Ahmad Al. Majali and Ghazi Al Assaf, "Long run and Short run Relationship between Stock Market Index and Main Macroeconomic Variable Performance, European scientific journal, vol 10(10),pp 18577881,April 2014.
[4] Ciner, C., "On the Long Run Relationship between Gold and Silver Prices-A Note", Global Finance Journal vol.12 (2, pp 299-303,2001.

[5] Kenji Kutsuna, Janet Kiholm Smith and Richard L.Smith, "Banking relationship and access to Equity Capital Markets: Evidence from Japan's main Bank System", Journal of Banking and Finance vol.31(2), pp 335-360,February2007.

[6] Bekrios D.Stelios and Diks G.H. Cees, "The Relationship between Crude Oil Spot and Futures Prices: Cointegration, Linear and Nonlinear Causality”, Journal of Energy Economics, Vol. 30, pp 2673-2685, 2008.

[7] Granger C W J. Some recent development in a concept of causality, Journal of Econometrics,Vol: 39, 199-211, 1988

[8] Johansen, S. 'Statistical analysis of cointegrating vectors,' Journal of Econometric Dynamics and Control, Vol:12, 231-54, 1988.

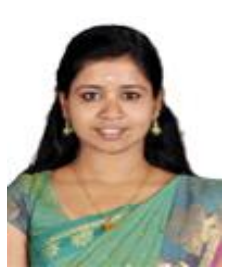

Hailing from god's own country, Kerala, myself Anjali A as my name implies, I welcome every new endeavour in the field of education. Born as a Capricorn, family and friends is my biggest asset. After completing my U.G. and P.G. in commerce from Sree Narayana Guru College, Calicut. I completed M.Phil from University of Calicut with specialization in finance. With a passion to learn and teach, I wish to pursue research and is currently working as an assistant professor of commerce in St Joseph College Devagiri (Autonomous) Calicut. 